\title{
Snowmelt and slushflows: hydrological and hazard implications
}

\author{
Martin Gude, ${ }^{1}$ Dieter Scherer ${ }^{2}$ \\ ${ }^{1}$ Department of Geography, University of Jena, Löbdergraben 32, D-07743 Jena, Germany \\ ${ }^{2}$ MCR Laboratory, University of Basel, Spalenring 145, CH-4055 Basel, Swilzerland
}

\begin{abstract}
In many high-latitude areas, slushflows occur frequently during the snowmelt period but information on the initiation mechanism is rare. Field observations and measurements of slushflows in northwestern Spitsbergen and in northern Sweden demonstrate the role of meltwater accumulation and the hydraulic pressure gradient in the release process. Snow metamorphism is revealed to be of minor importance in the observed events. The monitoring of water-pressure development in a saturated snow cover demonstrates that preferred release areas are within low-gradient valley sections, where meltwater inflow is higher than outflow.

Slushflows consist of mudflow-like flowage of water-saturated snow along stream courses. They represent transitional processes between fluvial floods and avalanches. On the other hand, they possess unique characteristics concerning release and movement. The comparative evaluation of definition items for fluvial floods, slushflows and avalanches offers basic data suitable for a risk assessment.
\end{abstract}

\section{INTRODUCTION}

The hydrological conditions of huge areas in Arctic and Alpine environments are strongly influenced by seasonal snow covers. Snowfall, rainfall on snow, and snowmelt as well as snow metamorphism are frequently accompanied by local displacements of snow and meltwater. Snow metamorphism often has destabilizing effects. High snowfall rates cause a significant increase in the weight of the snowpack that can lead to ruptures and the initiation of avalanches on steep slopes. On the other hand, melting results in a loss of mass on a steep slope due to the outflow of water. But, in low gradient slopes and valley sections, water from snowmelt or rainfall can accumulate, which also often results in the release of snow and water masses due to hydraulic effects. These mass displacements have been termed slushflows or slush avalanches (cf. e.g. Washburn and Goldthwait, 1958; Rapp, 1960; Hestnes, 1985; Nyberg, 1985). In order to describe the high-energy variant of slushflows more precisely, the term "slush torrent" is proposed instead of slush avalanche (Barsch and others 1993).

Triggering and movement of avalanches has been well studied and forecast systems are operational in the Alps and other mountains. Knowledge about release and movement conditions of slushflows is rare, although a number of analytical approaches have been undertaken (e.g. Nobles, 1966; Hestnes, 1985; Nyberg, 1985; Onesti, 1985). A hazardmanagement system similar to avalanche systems is not yet available. Data from measurements of the snowmelt-triggered release and movement process of slushflows in northwestern Spitsbergen and in northern Sweden offer new information as an important contribution to the development of a hazard-assessment system (Barsch and others, 1993; Gude and Scherer, 1995). This kind of risk-assessment system is required by railway and road authorities and could significantly improve the safety of hikers and skiers in tourist regions.

\section{RESEARCH AREAS AND METHODS}

The investigations of snowmelt-triggered slushflow initiation and movement are based on data from three field research campaigns in northwestern Spitsbergen and one campaign in Kärkevagge (northern Sweden). During the 3 years 1990-1992, fluvial dynamics and transport of sediments were studied in three catchments in northwestern Spitsbergen each of approximately $5 \mathrm{~km}^{2}$. At the start of any snowmelt season, a slushflow opened a channel and cleared it of snow. This took place at extremely different magnitudes: in 1990 and 1991, low-energy slushflows occurred, whereas in 1992 a large event with a velocity of at least $20 \mathrm{~m} \mathrm{~s}^{-1}$ shot down the valley and displaced a mass of $20000 \mathrm{t}$ of saturated snow and about $1500 \mathrm{t}$ of sediment in several waves lasting only a few minutes (Barsch and others, 1993). Based on the unexpected magnitude and the results from release and movement analyses, the hypothesis of meltwater accumulation leading to hydraulic pressure gradients as the primary release mechanism was developed (Scherer, 1994; Scherer and Parlow, 1994). This was to be tested in the Kärkerieppe, a small hanging cirque in Kärkevagge, where frequent slushflows had been reported by Rapp (1960) and Nyberg (1985). Measurements were concentrated on meltwater production, movement and storage. In addition, snowpack conditions were investigated frequently prior to and during water saturation. Drainage and accumulation of meltwater were monitored by means of dye-tracer and pressure-probe measurements. By chance, the release and flow of a slush torrent was observed. 


\section{HYDROLOGICAL IMPLICATIONS OF SLUSHFLOWS}

\section{Saturation of a valley snowpack}

Meltwater production by atmospheric effects on a snowpack is restricted to the uppermost part. Once meltwater is produced in an amount exceeding the irreducible content, it starts to percolate through the snow. Meltwater that is held by pore pressure yields only a few per cent by volume of snow (Colbeck, 1972). Subsequent metamorphism of the snow in the presence of the liquid phase leads to grain growth and the disappearance of smaller grains. This wetsnow metamorphism takes place within several hours to some days, especially when the whole pore volume is occupied by water, i.e. in saturated conditions ( $\mathrm{cf}$. reviews by Male (1980) or Colbeck (1987)). Snow metamorphism triggered by melting and percolating of water leads to increased hydraulic conductivity due to: (1) the coarsening of the grains and increasing distances between grains; (2) the higher pore volume and diameters; and (3) the weight lost of the ice matrix in saturated snowpacks (Male, 1980; Colbeck, 1987; Kattelmann, 1987). Fully saturated snow with low bond attraction between grains therefore has low resistance against erosion by the concentrated flow of water. An effect caused by this process is the erosion of drainage pipes within the snowpack.

Nevertheless, slope inclination remains an important invariant factor, since it determines the gradient at which gravity is effective. This implies that, on steep slopes, water drainage is faster than on shallower slopes.

\section{Water movement within the snowpack}

Movement of water within a saturated snow layer can be computed by adapting Darcy's formula. The meltwater-flow velocity is given by

$$
v=\kappa \rho g \mu^{-1} \Delta h \Delta x^{-1}
$$

where $\kappa, \rho$ and $\mu$ are the intrinsic permeability, density and viscosity of water; $g$ represents gravity. $\Delta h$ and $\Delta x$ are the vertical and horizontal differences of the water-table surface, i.e. the hydraulic gradient. The field measurements in Kärkerieppe offer adequate data for the hydraulic gradient but not for Darcy's $\kappa$. Direct measurements of the permeability in fully saturated snow are rare, so suitable values must be approximated. Colbeck (1972) calculated $10-40 \times 10^{-10} \mathrm{~m}^{2}$ and Kattelmann (1987) quoted approximately $3 \times 10^{-11} \mathrm{~m}^{2}$ associated with high wave speeds, based on measurements by different authors. Both values are similar to the permeability of sand for similar grain-sizes. Therefore, a value of

Table 1. Calculated velocities and discharge rates in Kärkerieppe, 1995

\begin{tabular}{lcccccc} 
Date & \multicolumn{2}{c}{$\begin{array}{c}\text { Discharge velocity } \\
\text { Gradient } \\
8^{\circ}\end{array}$} & $\begin{array}{c}\text { Gradient } \\
12^{\circ}\end{array}$ & $\begin{array}{c}\text { Discharge rate } \\
\text { Gradients } \\
8^{\circ} \text { and } 12^{\circ}\end{array}$ & $\begin{array}{c}\text { Depth of discharge layer } \\
\text { in two cross-profiles } \\
\text { Gradient } \\
8^{\circ}\end{array}$ & $\begin{array}{c}\text { Gradient } \\
12^{\circ}\end{array}$ \\
& \multicolumn{2}{c}{$\mathrm{m} \mathrm{s}^{-1}$} & $\mathrm{~m}^{3} \mathrm{~s}^{-1}$ & & $\mathrm{~m}$ & \\
\hline $12.00 / 30.05$ & $1.0 \times 10^{-4}$ & $2.3 \times 10^{-4}$ & $7.4 \times 10^{-4}$ & 0.2 & 0.1 \\
$12.00 / 01.06$ & $1.2 \times 10^{-4}$ & $2.3 \times 10^{-4}$ & $3.7 \times 10^{-3}$ & 0.7 & 0.4 \\
$12.00 / 03.06$ & $1.1 \times 10^{4}$ & $2.3 \times 10^{4}$ & $6.6 \times 10^{3}$ & 1.3 & 0.7
\end{tabular}

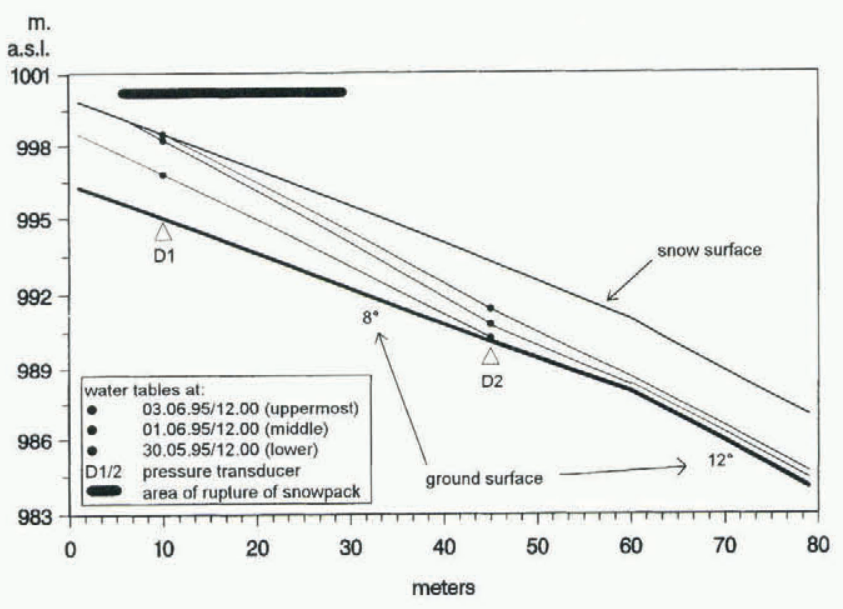

Fig. 1. Longitudinal profile of the Kärkerieppe valley section with slope change (water stages shown as dots; interpolation assumed and calculated).

$10^{-10} \mathrm{~m}^{2}$ is assumed to be appropriate, although snow metamorphism under saturated conditions should lead to even higher permeability. Tracer measurements of water drainage through a snow-filled channel indicated velocities of $10^{-1} \mathrm{~m} \mathrm{~s}^{-1}$ (Gude and Scherer, 1995), which implies an intrinsic permeability of approximately $10^{-8} \mathrm{~m}^{2}$. We assume this value is valid only for concentrated flow at the snow base, presumably accompanied by piping.

The Darcy formula allows calculations of flow velocities and discharge rates on the basis of measurements of depth and slope of the saturated layer in the cirque bottom of the Kärkerieppe (Table 1). The discharge rates are valid for the gently inclined upper part, where the water pressure was measured, as well as for the lower section with a steeper slope (Fig. 1). This holds because no remarkable water gains or losses occur between. The calculated depths of the discharge layer in the steeper part are significantly lower than in the low-gradient section. The mean decrease of angle in the water table from full saturation of $3.5 \mathrm{~m}$ (on 3 June) to a saturation depth of $0.7 \mathrm{~m}$ almost equals the angle of the water table in the steep part. Nevertheless, maximum decreases of angle are even higher, when the propagation of single water waves is considered. Whereas in the steep part the snow is saturated only to approximately $20 \%$ of the depth, the saturation in the upper part is $100 \%$.

A significant saturation layer has been present in the low-gradient section of Kärkerieppe since 31 May, and wetsnow metamorphism has subsequently weakened the snow cover. Preservation of former weak layers such as depth hoar is unlikely, because saturated metamorphism has developed well since this time (Male, 1980; Colbeck, 1987). Elder and Kattelmann (1993) have reported a "homogeneous snow pack of large rounded non-cohesive grains with a high free water content" prior to the release of a slushflow. The release of the slush torrent at $19.00 \mathrm{~h}$ on 3 June therefore is temporarily and spatially connected to the accelerated increase in the water table and the resulting hydraulic gradient. Further snow metamorphism is assumed to have had small influence, because rupture of the snow cover occurred at the base of the snowpack, where full saturation had developed for several days but not in the upper part with the increasing water level.

This type of rupture zone could be observed on Spitsbergen and also in the Kärkevagge and its surroundings. It 
Table 2. Terminology and characteristics of slushflows

\begin{tabular}{cc}
\hline $\begin{array}{c}\text { Minor slushflows } \\
\text { Sub-critical } \\
\text { turbulent flow }\end{array}$ & $\begin{array}{c}\text { Slush torrents } \\
\text { Supercritical } \\
\text { shooting movement }\end{array}$ \\
\hline \multicolumn{2}{c}{ Froude number } \\
$0.3-3 \mathrm{~m} \mathrm{~s}^{-1}$ & $>2$ \\
\hline
\end{tabular}

has to be stressed that the prevention of open flow in a channel due to snow-filling is prerequisite for this sort of hydraulic release (cf. Nobles, 1966; Nyberg, 1985; Elder and Kattelmann, 1993).

\section{PHYSICAL CHARACTERISTICS OF SLUSHFLOWS}

Due to rupture of the snowpack in a zone with a high water level, a mass of slush is released abruptly. The documented observations and measurements in northwestern Spitsbergen and in the Kärkevagge area, and also numerical analyses, indicate that it is necessary two distinguish two types of slushflow to account for their different flow characteristics (Barsch and others, 1993).

Acceleration of the flow is forced by the slope of the channel and also by confinement in a narrow channel, which results in higher flow depths. This is counteracted by the snow within the channel retarding the flow by energy consumption for erosion and entrainment of additional snow and water masses. High amounts of slush that reach steep and confined channel gradients will be accelerated and move in a similar way to debris flows or dam-break floods. An important factor is the addition of mass by entrainment of snow and water from the channel. These highenergy flows, which shoot downstream almost independently of channel roughness, we term slush torrents. On the other hand, in most cases, low initial masses are only able to plough through a snow-filled channel. Entrainment of new slush masses almost equals the simultaneous deposition on levées. This type is termed a minor slushflow. Our proposed characteristics of minor slushflows and slush torrents are summarized in Table 2.

\section{HAZARD IMPLICATIONS}

\section{Relation to fluvial processes and avalanches}

Slush-flows are closely connected to the fluvial environment, which refers to the affected areas as well as to the hydrological process characteristics. The first publication with a definition of this topic, drafted by Washburn and Goldthwait (1958), had already indicated this relation. Since then, about 30 publications in international journals have quoted slush movements and most of them have been confined to channels, valley bottoms or chutes (cf. e.g. Hestnes, 1985; Nyberg, 1985; Onesti, 1985; André, 1993).

Sincesaturation of a deepsnowpack is a prerequisite for the release of a slushflow, the preferred area of initiation is a valley section with a high inflow from the adjacent slopes but low outflow through a channel. On straight slopes, a remarkably long distance with a gentle gradient is needed to generate a saturated layer of a certain depth, as described by Male (1980). In Arctic, and especially in Alpine environments, this type of long and gently inclined slope is rare except for glacier surfaces. Therefore, it is not surprising that slushflows have been reported from ice shields, and the slush zone of valley glaciers is also a well-known phenomenon (Nobles, 1966).

Besides the release zone and the flow path, the run-out zone fans of slushflows are akin to fluvial fans. Analyses of fans in northwestern Spitsbergen have stressed that slushflow fans are built up at the outlets of valleys similar to those of fluvial fans but they can be identified because of their characteristic shape and sediment features (Nyberg, 1985; Barsch and others, 1993). Consequently, sediment fans can offer important data on the magnitude and frequency of slushflows (cf. e.g. André, 1993).

The observed slushflow tracks in northern Sweden and northwestern Spitsbergen (a total number of approximately 20 tracks) were restricted to channel sections with almost intact snow cover. These channels are opened by slushflows and herebyopen-waterflowisenabled.ThiscorrespondstotheinitialdefinitiongivenbyWashburnandGoldthwait (1958). In this context, slushflows represent animportant element of theseasonal course offluvial activity. Since high amounts of meltwater can be stored temporarily in channel snowpacks, peak floods in the form of slush torrents can be several orders of magnitude higher than fluvial floods (Barsch and others, 1994).

The occurrence of slushflows has often been discussed in connection with avalanching, as a result of which several

Table 3. Summary of typical characteristics of fluvial floods, slushflows and avalanches, based on field studies and publications

\begin{tabular}{|c|c|c|c|}
\hline & Fluvial floods & Slush-flows & Avalanches \\
\hline Preconditions & $\begin{array}{l}\text { Meltwater production and/or } \\
\text { rain delivery to the open channel }\end{array}$ & $\begin{array}{l}\text { Meltwater production and/or rain accum- } \\
\text { ulation in the channel snow cover }\end{array}$ & $\begin{array}{l}\text { Snowpack properties or additional } \\
\text { snow load }\end{array}$ \\
\hline $\begin{array}{l}\text { Release } \\
\text { process }\end{array}$ & Discharge of water & $\begin{array}{l}\text { Abrupt rupture of saturated snowpack } \\
\text { (water content appr. } 50 \% \text { ) }\end{array}$ & $\begin{array}{l}\text { Abrupt rupture of dry or wet snowpack } \\
\text { (water content }<10 \%\end{array}$ \\
\hline Release zone & Channel & Low-gradient channel (or slope) section & Steep slope or chute \\
\hline $\begin{array}{c}\text { Sediment } \\
\text { content }\end{array}$ & $\begin{array}{l}\text { Small amounts of sediments } \\
\left(\text { normally }<1 \mathrm{~kg} \mathrm{~m}^{-3}\right)\end{array}$ & $\begin{array}{l}\text { Frequently high sediment content } \\
\quad\left(\text { up to } 10 \mathrm{~kg} \mathrm{~m}^{-3}\right)\end{array}$ & Occasionally high sediment contents \\
\hline $\begin{array}{l}\text { Run-out } \\
\text { process }\end{array}$ & Sediment deposition & Snow and sediment deposition & Snow and sediment deposition \\
\hline Run-out zone & Channel gradient decrease and/or widening & Channel gradient decrease and/or widening & Slope gradient decrease \\
\hline
\end{tabular}


authors have used the term "slush avalanche" (e.g. Rapp, 1960; Hestnes, 1985). However, the term implies a mixing with wet-snow avalanches, although several process characteristics indicate that a separate definition is to be recommended. As demonstrated above, snow metamorphism is assumed to be a necessary but not sufficient factor in the development of a critical mass of slush, but the factor determining the release is the hydraulics of the water table. These release conditions are not covered by the avalanche definition. Furthermore, avalanches and slushflows affect different areas, depending on the initiation factors. The typical slope thresholds for the release areas of avalanches are greater than $25^{\circ}$ but slushflows most frequently occur on slopes of less than $15^{\circ}$ and have been reported to have been released on slopes of $2^{\circ}$ (Rapp, 1960; Nobles, 1966; Scherer, 1994).

Despite the different release conditions, transitional processes are possible. Prominent is the triggering of slushflows by avalanches that run into saturated snow covers in channels and mobilize slush masses. Without accounting for the significant amount of meltwater incorporated into the flow, the overcoming of long and gently inclined valley sections cannot be explained.

Consequently, slushflows represent a transitional process related to fluvial floods and avalanches, but have to be separated from these processes because of their characteristic mechanisms of initiation, movement and run-out (summarized in Table 3). On the other hand, it is recommended that slush torrents (slush avalanches) be included in the overall definition of slushflows, because these mass movements have similar release and flow features.

\section{Hazard assessment}

In summary, the discussion of the release processes of slushflows and their relation to fluvial activity and to avalanches provides information suitable for the development of a hazard-assessment system. An assessment of hazardous impacts requires an evaluation of affected areas as well as the dangerous periods.

Consideration of affected and endangered areas comprises both the hydrological and terrain features, as well as the flow characteristics. They can be evaluated by accounting for the following subjects:

The areas, where the initiation of slushflows typically takes place, are low-gradient valley sections.

Water accumulation is most effective in areas with permafrost or impermeable solid rocks.

Due to the fact that slushflows can flow for remarkable distances even with extremely low gradients, a long down-valley section may be affected and is highly endangered.

Slush-flows are frequent in the Arctic but have also been reported from lower-latitude Alpine environments (e.g. Elder and Kattelmann, 1993).

The periods that possess high risks of slushflow release have been given by the meteorological and snow hydrological conditions.

The most important factors are:

Considerable amounts of meltwater or rain must be available for water accumulation in valley sections. Therefore, snowmelt or rainfall is a prerequisite for the release of slushflows.
Accumulation of water in channels is only effective when the snowpack is almost intact. Consequently, slushflows of the type reported are restricted to periods prior to the main snowmelt period in catchments.

A hazard evaluation covering hazardous areas and periods requires both terrain analyses and meteorological and snow-hydrological monitoring. Information from these data sources must then be included in a numerical model.

Comprehensive experience in avalanche-risk assessment is an enormous benefit for the development of a model for slushflow risk evaluation but information on the release and flow characteristics is still limited.

\section{ACKNOWLEDGEMENTS}

The co-ordinator of the "Geoscientific Spitsbergen-Expeditions SPE90-92”, W. Blümel (Stuttgart, Germany), A. Rapp, P. Schlyter (Lund, Sweden), the Abisko Scientific Research Station and all colleagues assisting the field and laboratory work are gratefully acknowledged. The projects were supported by the German Science Foundation, the Swiss National Science Foundation and the Swiss Academy of Science.

\section{REFERENCES}

André, M.-F. 1993. Les versants du Spitsberg: approche géographique des paysages polaires. Nancy, Presses Universitaires de Nancy. (Géographie et Environnement.)

Barsch, D., M. Gude, R. Mäusbacher, G. Schukraft, A. Schulte and D. Strauch. 1993. Slush stream phenomena - process and geomorphic impact. Z Geomorphol., Supplementband 92, 39-53.

Barsch, D., M. Gude, R. Mäusbacher, G. Schukraft and A. Schulte. 1994. Recent fluvial sediment budgets in glacial and periglacial environments, NW Spitsbergen. Z. Geomorphol., Supplementband 97, 111-122.

Colbeck, S. C. 1972. A theory of water percolation in snow. J. Glaciol., 11 (63), 369-385.

Colbeck, S. C. 1987. A review of the metamorphism and classification of seasonal snow cover crystals. International Association of Hydrological Sciences Publication 162 (Symposium at Davos 1986-Avalanche Formation, Movement and Effects), 3-34.

Elder, K. and R. Kattelmann. 1993. A low-angle slushflow in the Kirgiz Range, Kirgizstan. Permafrost Periglacial Processes, 4(4), 301-310.

Gude, M. and D. Scherer. 1995. Snowmelt and slush torrents - preliminary report from a field campaign in Kärkevagge, Swedish Lappland. Geogr. Ann., 77A(4), $199-206$.

Hestnes, E. 1985. A contribution to the prediction of slush avalanches. Ann. Glaciol., 6, 1-4.

Kattelmann, R. 1987. Some measurements of water movement and storage in snow. International Association of Hydrological Sciences Publication 162 (Symposium at Davos 1986 - Avalanche Formation, Movement and Effects), 245-254.

Male, D. H. 1980. The seasonal snowcover. In Colbeck, S. C., ed. Dynamics of snow and ice masses. New York, Academic Press, 305-395.

Nobles, L. H. 1966. Slush avalanches in northern Greenland and the classification of rapid mass movements. International Association of Scientific Hydrology Publication 69 (Symposium at Davos 1965 - Scientific Aspects of Snow and Ice Avalanches), 267-272.

Nyberg, R. 1985. Debris flows and slush avalanches in northern Swedish Lappland-distribution and geomorphological significance. Medd. Lunds Univ. Geogr. Inst. Avh. 97.

Onesti, L. J. 1985. Meteorological conditions that initiate slushflows in the central Brooks Range, Alaska. Ann. Glaciol., 6, 23-25.

Rapp, A. 1960. Recent development of mountain slopes in Kärkevagge and surroundings, northern Scandinavia. Geogr. Ann., 42(2-3), 65-200.

Scherer, D. 1994. Slush stream initiation in a High Arctic drainage basin in NW-Spitsbergen. Stratus (Basel) 1.

Scherer, D. and E. Parlow. 1994. Terrain as an important controlling factor for climatological, meteorological and hydrological processes in NWSpitsbergen. Z Geomorphol. Supplementband 97, 175-193.

Washburn, A. L. and R. P. Goldthwait. 1958. Slushflows. (Abstract.) Geol. Soc. Am. Bull., 69, 1657-1658. 